Supporting Information

\title{
Tuning Electron-Conduction and Spin Transport in Magnetic Iron Oxide Nanoparticle Assemblies via Tetrathiafulvalene-Fused Ligands
}

\author{
Zhong-Peng Lv, ${ }^{\dagger}$ Zhong-Zhi Luan, ${ }^{\ddagger}$ Hai-Ying Wang, ${ }^{\dagger}$ Sheng Liu, ${ }^{\dagger}$ Cheng-Hui Li, ${ }^{\dagger}$ Di Wu,, \\ Jing-Lin Zuo, ${ }^{* \dagger}$ Shouheng Sun*»
}

'State Key Laboratory of Coordination Chemistry, School of Chemistry and Chemical Engineering, Collaborative Innovation Center of Advanced Microstructures, Nanjing University, Nanjing 210093, P. R. China

${ }^{*}$ National Laboratory of Solid State Microstructures, Department of Physics, Collaborative Innovation Center of Advanced Microstructures, Nanjing University, Nanjing 210093, P. R. China

${ }^{\S}$ Department of Chemistry, Brown University, Providence, Rhode Island 02912, USA

\section{Experimental Section}

Precursors for NP Synthesis. Iron(III) acetylacetonate $\left(\mathrm{Fe}(\mathrm{acac})_{3}, 98 \%\right)$ was purchased from J\&K Scientific Ltd (Shanghai, China). Benzyl ether (98\%) and oleylamine (OA, 80\%-90\%) were purchased from Aladdin Industrial Corporation (Shanghai, China). Oleic acid (OC, AR) was purchased from Sinopharm Chemical Reagent Co. (Shanghai, China).

Synthesis of TTF Ligands. The precursors, compound $\mathbf{1},{ }^{1}$ compound $3,{ }^{2}$ compound $\mathbf{8}^{3}$ and 4,5-bis(propylthio)-1,3-dithiole-2-one ${ }^{4,5}$ were synthesized according literature method. Lithium bromide anhydrous $(\mathrm{LiBr} \geq 99 \%)$ was purchase from Alfa Aesar Asia (Shanghai, China).

\footnotetext{
*Email: zuojl@nju.edu.cn, ssun@brown.edu.
} 
Potassium sulfide $\left(\mathrm{K}_{2} \mathrm{~S}, 43 \%\right)$, cuprous oxide $\left(\mathrm{Cu}_{2} \mathrm{O}, 98 \%\right)$ and ethyl acetoacetate (EAA, $98 \%$ ) were purchase from Sinopharm Chemical Reagent Co., Ltd (Shanghai, China). Other reagents and solvents were purchased at reagent grade and used without further purification.

Synthesis of $\boldsymbol{L}_{\boldsymbol{I}}$

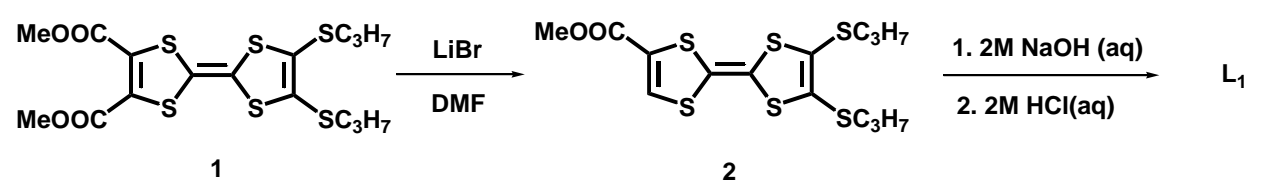

The compound $\mathbf{2}$ was synthesized from $\mathbf{1}$ according to the literature method. ${ }^{6}$ A mixture of $\mathbf{1}$ (196 mg, $0.42 \mathrm{mmol}), \mathrm{LiBr}(656 \mathrm{mg}, 7.6 \mathrm{~mol})$ and DMF $(8 \mathrm{ml})$ were stirred at $85{ }^{\circ} \mathrm{C}$. After $5 \mathrm{~h}$ (reaction was monitored by TLC), brine $(10 \mathrm{ml})$ was added. The mixture was extracted three times with ethylacetate and the organic phase was washed three times with brine, dried over $\mathrm{MgSO}_{4}$. The solvent was removed and the crude product was purified by silica gel column chromatography with petroleum ether/ $\mathrm{CH}_{2} \mathrm{Cl}_{2}$ as eluent to give 2 as an orange oil (150 mg, 0.37 mmol, 87\%). ${ }^{1} \mathrm{H}$ NMR (500 MHz $\left.\mathrm{CDCl}_{3}-d_{1}, \delta\right): 5.37$ (m, $\left.1 \mathrm{H}, \mathrm{CH}\right), 3.85\left(\mathrm{~s}, 3 \mathrm{H}, \mathrm{CH}_{3}\right), 2.83$ (s, 4H, $\left.\mathrm{CH}_{2}\right), 1.70\left(\mathrm{~h}, J=7.2 \mathrm{~Hz}, 4 \mathrm{H}, \mathrm{CH}_{2}\right), 1.04\left(\mathrm{t}, J=7.3 \mathrm{~Hz}, 6 \mathrm{H}, \mathrm{CH}_{3}\right)$. EI-MS m/z: calcd for $\mathrm{C}_{14} \mathrm{H}_{18} \mathrm{O}_{2} \mathrm{~S}_{6}[\mathrm{M}]^{+}$, 409.96; found 410.0.

$\mathbf{L}_{1}: 2(205 \mathrm{mg}, 0.5 \mathrm{mmol})$ was dissolved in MeOH:THF (1:1 v/v) $(25 \mathrm{~mL})$. Then $2 \mathrm{M} \mathrm{KOH}$ aqueous solution $(0.75 \mathrm{~mL})$ was added and the reaction solution was refluxed at $80^{\circ} \mathrm{C}$ overnight. After solvent removal, water was added and the solution was then acidified to $\mathrm{pH}=3$ with $12 \mathrm{M}$ $\mathrm{HCl}$. The precipitate was collected by filtration and dried in vacuum to obtain $\mathbf{L}_{\mathbf{1}}$ as a red powder (153 mg, $0.43 \mathrm{mmol}, 77 \%) .{ }^{1} \mathrm{H}$ NMR (500MHz DMSO- $\left.d_{6}, \delta\right): 13.85$ (s, 1H, COOH), 7.69 (s, 1H, CH), 2.85 (t, $\left.J=7.1 \mathrm{~Hz}, 4 \mathrm{H}, \mathrm{CH}_{2}\right), 1.58$ (h, $\left.J=7.3 \mathrm{~Hz}, 4 \mathrm{H}, \mathrm{CH}_{2}\right), 0.97$ (t, $J=7.3 \mathrm{~Hz}, 6 \mathrm{H}$, $\mathrm{CH}_{3}$ ). ESI-MS m/z: calcd for $\mathrm{C}_{13} \mathrm{H}_{16} \mathrm{O}_{2} \mathrm{~S}_{6}[\mathrm{M}-\mathrm{H}]^{-}, 394.95$; found 394.58 . 
Synthesis of $\boldsymbol{L}_{2}$

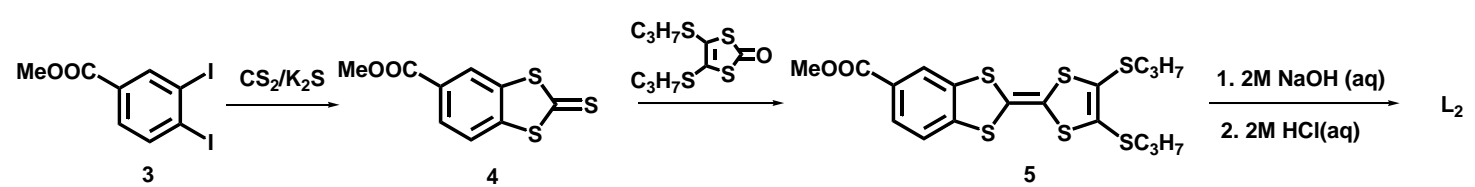

To synthesize the compound $4, \mathrm{~K}_{2} \mathrm{~S}(1.64 \mathrm{~g}), \mathrm{CS}_{2}(0.8 \mathrm{~mL})$ and DMF $(8 \mathrm{~mL})$ were mixed and stirred at room temperature for $2 \mathrm{~h}$. Then $3(1.78 \mathrm{~g}, 4 \mathrm{mmol})$ was added and the reaction was held at $80{ }^{\circ} \mathrm{C}$ for $12 \mathrm{~h}$. After cooling to room temperature, the reaction mixture was poured into water and filtrated. The crude yellow precipitate was purified by a column on silica gel using petroleum ether/ $\mathrm{CH}_{2} \mathrm{Cl}_{2}$ as eluent to afford 4 as a light yellow solid (852 mg, $3.32 \mathrm{mmol}, 83 \%$ ). ${ }^{1} \mathrm{H}$ NMR (500 MHz $\left.\mathrm{CDCl}_{3}-d_{1}, \delta\right): 8.17(\mathrm{~d}, J=1.6 \mathrm{~Hz}, 1 \mathrm{H}, \mathrm{Ar} \mathrm{H}), 8.06(\mathrm{dd}, J=8.4,1.7 \mathrm{~Hz}, 1 \mathrm{H}$, $\operatorname{Ar~H}), 7.57$ (d, $J=8.4 \mathrm{~Hz}, 1 \mathrm{H}, \operatorname{Ar} \mathrm{H}), 3.98$ (d, $\left.J=1.4 \mathrm{~Hz}, 3 \mathrm{H}, \mathrm{CH}_{3}\right)$. EI-MS m/z: calcd for $\mathrm{C}_{9} \mathrm{H}_{6} \mathrm{O}_{2} \mathrm{~S}_{3}[\mathrm{M}]^{+}, 241.95$; found 242.0.

To synthesize the compound 5, under a nitrogen atmosphere, a mixture of 4 (512 $\mathrm{mg}, 2$ mmol), 4,5-bis(propylthio)-1,3-dithiole-2-one (2.2 mmol), $\mathrm{P}(\mathrm{OEt})_{3}(10 \mathrm{~mL})$ and toluene $(10 \mathrm{~mL})$ was reacted at $120^{\circ} \mathrm{C}$ for $5 \mathrm{~h}$ and then cooled to room temperature. The solvent was removed and the crude was purified by silica gel column chromatography with petroleum ether $/ \mathrm{CH}_{2} \mathrm{Cl}_{2}$ as eluent to afford 5 as a yellow solid. (256 mg, $0.54 \mathrm{mmol}, 27 \%$ ). ${ }^{1} \mathrm{H}$ NMR (500 $\mathrm{MHz} \mathrm{CDCl}_{3}-d_{1}$,

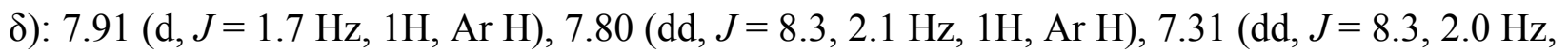
1H, Ar H), 3.93 (s, 4H, $\left.\mathrm{CH}_{3}\right), 2.83$ (td, $\left.J=7.2,3.5 \mathrm{~Hz}, 4 \mathrm{H}, \mathrm{CH}_{2}\right), 1.70\left(\mathrm{~h}, J=7.4 \mathrm{~Hz}, 4 \mathrm{H}, \mathrm{CH}_{2}\right)$, $1.05\left(\mathrm{t}, J=7.2,6 \mathrm{H}, \mathrm{CH}_{3}\right)$. EI-MS m/z: calcd for $\mathrm{C}_{18} \mathrm{H}_{20} \mathrm{O}_{2} \mathrm{~S}_{6}[\mathrm{M}]^{+}, 459.98$; found 459.9 .

The orange solid $\mathbf{L}_{\mathbf{2}}$ was obtained from $\mathbf{5}$ by a procedure similar to that for synthesizing $\mathbf{L}_{\mathbf{1}}$. Yield: 93\%. ${ }^{1} \mathrm{H}$ NMR (500 MHz DMSO-d $\left.6, \delta\right): 13.17$ (s, $\left.1 \mathrm{H}, \mathrm{COOH}\right), 8.07(\mathrm{~d}, J=1.7 \mathrm{~Hz}, 1 \mathrm{H}$, Ar H), $7.76(\mathrm{dd}, J=8.3,1.7 \mathrm{~Hz}, 1 \mathrm{H}, \mathrm{Ar} \mathrm{H}), 7.65$ (d, $J=8.3 \mathrm{~Hz}, 1 \mathrm{H}, \mathrm{Ar} \mathrm{H}), 2.86(\mathrm{td}, J=7.1,2.3$ $\mathrm{Hz}, 4 \mathrm{H}, \mathrm{CH}_{2}$ ), 1.59 (h, $\left.J=7.2 \mathrm{~Hz}, 4 \mathrm{H}, \mathrm{CH}_{2}\right), 0.97$ (t, $J=7.3 \mathrm{~Hz}, 6 \mathrm{H}, \mathrm{CH}_{3}$ ). ESI-MS m/z: calcd for $\mathrm{C}_{17} \mathrm{H}_{18} \mathrm{O}_{2} \mathrm{~S}_{6}[\mathrm{M}-\mathrm{H}]^{-}$, 444.96; found 444.99. 
Synthesis of $\boldsymbol{L}_{3}$

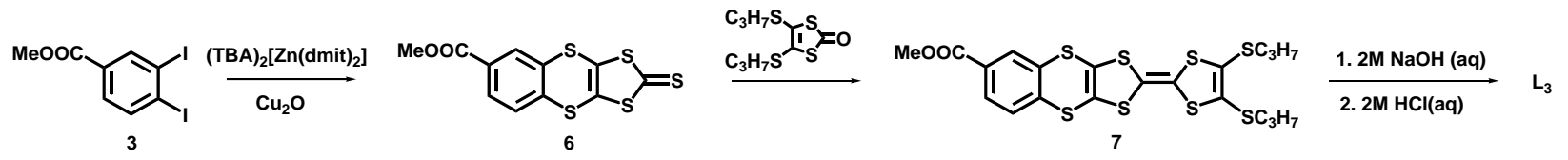

The compound $\mathbf{6}$ was synthesized from 3 and $(\mathrm{TBA})_{2}\left[\mathrm{Zn}(\mathrm{DMIT})_{2}\right]$ using literature methods. ${ }^{7}$ In a typical synthesis process, $(\mathrm{TBA})_{2}\left[\mathrm{Zn}(\mathrm{dmit})_{2}\right](1.59 \mathrm{~g}, 1.69 \mathrm{mmol}), 3(1.44 \mathrm{~g}, 3.72$ $\mathrm{mmol}$ ), $\mathrm{Cu}_{2} \mathrm{O}$ (48.6 mg, $\left.0.34 \mathrm{mmol}\right)$, DMF ( $3 \mathrm{~mL}$ ) and ethyl acetoacetate (EAA, $88.5 \mathrm{mg}, 0.68$ mmol) were mixed under nitrogen atmosphere. The reaction was kept at $80^{\circ} \mathrm{C}$ for $12 \mathrm{~h}$ and then cooled to room temperature. The crude product was obtained by extract the reaction solution with $\mathrm{CH}_{2} \mathrm{Cl}_{2}$, washed with water, brine, and dried over $\mathrm{Na}_{2} \mathrm{SO}_{4}$. The solvent was removed and the crude was purified by a short column on silica gel using petroleum ether/ $\mathrm{CH}_{2} \mathrm{Cl}_{2}$ as eluent to afford 6 as a yellow solid (725 mg, $2.19 \mathrm{mmol}, 59 \%) .{ }^{1} \mathrm{H}$ NMR (500 $\left.\mathrm{MHz} \mathrm{CDCl}_{3}-d_{1}, \delta\right): 8.15$ (s, 1H, Ar H), 8.03 (d, $J=8.2 \mathrm{~Hz}, 1 \mathrm{H}, \operatorname{Ar} \mathrm{H}), 7.57$ (d, $J=8.1 \mathrm{~Hz}, 1 \mathrm{H}, \mathrm{Ar} \mathrm{H}), 3.97$ (s, 3H, $\mathrm{CH}_{3}$ ). EI-MS m/z: calcd for $\mathrm{C}_{11} \mathrm{H}_{6} \mathrm{O}_{2} \mathrm{~S}_{5}[\mathrm{M}]^{+}$, 329.90; found 329.9 .

The orange yellow solid compound 7 was obtained by a procedure similar to that for synthesizing 5 from 6 and 4,5-bis(propylthio)-1,3-dithiole-2-one. Yield: 31\%. ${ }^{1} \mathrm{H}$ NMR (500 $\left.\mathrm{MHz} \mathrm{CDCl}_{3}-d_{1}, \delta\right): 8.07$ (s, 1H, Ar H), 7.94 (d, $\left.J=7.9 \mathrm{~Hz}, 1 \mathrm{H}, \mathrm{Ar} \mathrm{H}\right), 7.48(\mathrm{~d}, J=8.2 \mathrm{~Hz}, 1 \mathrm{H}$, Ar H), 3.94 (s, 3H, $\left.\mathrm{CH}_{3}\right), 2.82$ (t, $\left.J=7.2 \mathrm{~Hz}, 4 \mathrm{H}, \mathrm{CH}_{2}\right), 1.69$ (h, $\left.J=7.2 \mathrm{~Hz}, 4 \mathrm{H}, \mathrm{CH}_{2}\right), 1.04$ (t, $J$ $=7.3 \mathrm{~Hz}, 6 \mathrm{H}, \mathrm{CH}_{3}$ ). EI-MS m/z: calcd for $\mathrm{C}_{20} \mathrm{H}_{20} \mathrm{O}_{2} \mathrm{~S}_{8}[\mathrm{M}]^{+}, 547.92$; found 547.8 .

The brownish solid $\mathbf{L}_{\mathbf{3}}$ was obtained from $\mathbf{7}$ by a procedure similar to that for synthesizing $\mathbf{L}_{\mathbf{1}}$. Yield: 86\%. ${ }^{1} \mathrm{H}$ NMR (500 MHz DMSO- $\left.d_{6}, \delta\right): 7.99(\mathrm{~d}, J=1.6 \mathrm{~Hz}, 1 \mathrm{H}, \mathrm{Ar} \mathrm{H}), 7.89(\mathrm{dd}, J=$ 8.0, 1.7 Hz, 1H, Ar H), 7.61 (d, $J=8.0 \mathrm{~Hz}, 1 \mathrm{H}, \mathrm{Ar} \mathrm{H}), 2.86$ (t, $\left.J=7.0 \mathrm{~Hz}, 4 \mathrm{H}, \mathrm{CH}_{2}\right), 1.58$ (h, $J=$ $\left.7.2 \mathrm{~Hz}, 4 \mathrm{H}, \mathrm{CH}_{2}\right), 0.96\left(\mathrm{t}, J=7.3 \mathrm{~Hz}, 6 \mathrm{H}, \mathrm{CH}_{3}\right.$ ), no peak $>10 \mathrm{ppm}$ for COOH. ESI-MS m/z: calcd for $\mathrm{C}_{19} \mathrm{H}_{18} \mathrm{O}_{2} \mathrm{~S}_{8}[\mathrm{M}-\mathrm{H}]^{-}, 532.91$; found 532.89 . 
Synthesis of $\boldsymbol{L}_{1}$,

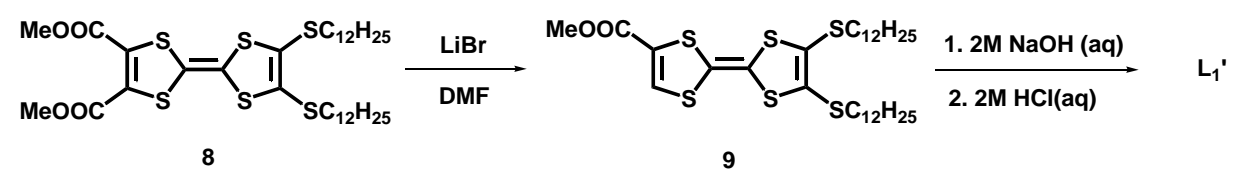

The orange solid $\mathbf{9}$ was obtained from $\mathbf{8}$ by a procedure similar to that for synthesizing 2 . Yield: $85 \% .{ }^{1} \mathrm{H}$ NMR (500 MHz CDCl $\left.{ }_{3}-d_{1}, \delta\right) 7.36(\mathrm{~m}, 1 \mathrm{H}, \mathrm{CH}), 3.84\left(\mathrm{~s}, 3 \mathrm{H}, \mathrm{CH}_{3}\right), 2.84(\mathrm{t}, J=$ $\left.7.4 \mathrm{~Hz}, 4 \mathrm{H}, \mathrm{CH}_{2}\right), 1.65$ (p, $\left.J=7.4 \mathrm{~Hz}, 4 \mathrm{H}, \mathrm{CH}_{2}\right), 1.42\left(\mathrm{p}, J=7.4 \mathrm{~Hz}, 4 \mathrm{H}, \mathrm{CH}_{2}\right), 1.35-1.29(\mathrm{~m}$, $\left.32 \mathrm{H}, \mathrm{CH}_{2}\right), 0.89\left(\mathrm{t}, J=6.5 \mathrm{~Hz}, 6 \mathrm{H}, \mathrm{CH}_{3}\right)$. EI-MS m/z: calcd for $\mathrm{C}_{32} \mathrm{H}_{54} \mathrm{O}_{2} \mathrm{~S}_{6}[\mathrm{M}]^{+}, 622.24$; found 622.0 .

The red solid $\mathbf{L}_{\mathbf{1}}$ ' was obtained from $\mathbf{9}$ by a procedure similar to that for synthesizing $\mathbf{L}_{\mathbf{1}}$. Yield: 79\%. ${ }^{1} \mathrm{H}$ NMR (500 MHz DMSO- $\left.d_{6}, \delta\right) 7.45$ (s, $\left.1 \mathrm{H}, \mathrm{CH}\right), 2.84\left(\mathrm{t}, J=7.3 \mathrm{~Hz}, 4 \mathrm{H}, \mathrm{CH}_{2}\right.$ ), $1.55\left(\mathrm{p}, J=7.3 \mathrm{~Hz}, 4 \mathrm{H}, \mathrm{CH}_{2}\right), 1.36\left(\mathrm{p}, J=7.1 \mathrm{~Hz}, 4 \mathrm{H}, \mathrm{CH}_{2}\right), 1.29-1.23\left(\mathrm{~m}, 32 \mathrm{H}, \mathrm{CH}_{2}\right), 0.85(\mathrm{t}, J$ $=6.7 \mathrm{~Hz}, 6 \mathrm{H}, \mathrm{CH}_{3}$ ), no peak $>10$ ppm for COOH. ESI-MS m/z: calcd for $\mathrm{C}_{31} \mathrm{H}_{52} \mathrm{O}_{2} \mathrm{~S}_{6}[\mathrm{M}-\mathrm{H}]^{-}$, 647.23; found 646.82 .

Characterization. ${ }^{1}$ H-NMR spectra were performed on a Bruker AVANCE DRX-500 NMR spectrometer at room temperature. The signal from the specific solvent was used as an external standard for the determination of the chemical shift ( $\mathrm{CDCl}_{3}-d_{1}$ and DMSO- $d_{6}$ TMS: $\left.0.00 \mathrm{ppm}\right)$. Mass spectra were recorded with a Macromass GC TOF for EI-MS and Thermo Fisher LCQ Fleet for ESI-MS. The Fe content of the NPs was determined by flame atomic absorption spectrometry (F-AAS) on a Hitachi 180-80 instrument was listed in Table S2. Elements were also analyzed by energy dispersive X-ray (EDX) spectroscopy on a Hitachi S-4800 field emission scanning electron microscope (FE-SEM) and the analytic results were given in Table S3 and Table S4. The sample pellets were prepared by press the powders on a copper foil substrate under pressure of $30 \mathrm{MPa}$. The sample thickness was $50 \mu \mathrm{m}$ or thicker to ensure that 
the secondary electrons detected by EDX were all from the samples. The infrared spectra were recorded as a $\mathrm{KBr}$ pellet on a Bruker TENSOR 27 FT-IR spectrometer in transmission mode from 400 to $4000 \mathrm{~cm}^{-1}$ at a resolution of $1 \mathrm{~cm}^{-1}$ and 40 scans. Electronic absorption spectra were recorded on a Shimadzu, UV $2550 \mathrm{UV}$-vis spectrometer in a $10 \mathrm{~mm}$ path length cuvette.

TEM and HRTEM imagines of the NPs were performed on JEOL JEM 2100 microscope operated at $200 \mathrm{kV}$. TEM samples were prepared by dropping hexane dispersion of the OA-NPs or chloroform dispersion of the modified NPs onto carbon-coated copper grids and drying at room temperature. Then, 8 pictures with in total 2305 particles were used to evaluate the particle size distribution of OA-NPs by image digitization software ImageJ. ${ }^{8}$ A bin size of $0.1 \mathrm{~nm}$ was chosen for the creation of the particle size histogram. The NP interspaces of these samples were obtained statistically from their TEM images with 200 measurements each by software Nano Measurer. 9

Power XRD measurements were performed on a Bruker D8 ADVANCE using a $\mathrm{Cu} K \alpha$ radiation $(\lambda=0.15410 \mathrm{~nm})$. The measurement was performed between the angles of 20 and $80^{\circ}$. The dimension of crystalline domain in $\mathrm{Fe}_{3} \mathrm{O}_{4}$ nanoparticles was calculated following Scherrer's equation. Powder SAXS measurements were performed on an Anton Paar SAXSess mc2 in the transmission mode using a $\mathrm{Cu} K \alpha$ radiation $(\lambda=0.15410 \mathrm{~nm})$ between 0.15 and $10^{\circ}$. The average NP interspace was calculated based on the length of the scattering vector $q=4 \pi \times \sin \theta / \lambda$ and Bragg equation $2 d \times \sin \theta=\lambda$,

$$
D_{\mathrm{i}}=2 \pi / q_{1}-2 \pi / q_{2}
$$

where $D_{\mathrm{i}}$ represents the average NP interspace, $q_{1}$ is the length of the scattering vector for the peak represents the average distance between centers of adjacent nanoparticles, $q_{2}$ is the length of the scattering vector for the peak represents the average diameter of NP cores.

Magnetic hysteresis loops of the NPs were measured with a Quantum Design MPMS-SQUID-VSM magnetometer in the temperature at $100 \mathrm{~K}$. The magnetic field sweeping rate is 500 Oe per second. The measured magnetic moment (emu) was then divided by the mass 
of the $\mathrm{Fe}_{3} \mathrm{O}_{4}(\mathrm{~g})$ to obtain $M\left(\mathrm{emu} / \mathrm{g} \mathrm{Fe}_{3} \mathrm{O}_{4}\right)$. The $\mathrm{Fe}_{3} \mathrm{O}_{4}$ mass was the product of the NP mass and the $\mathrm{Fe}_{3} \mathrm{O}_{4}$ percentage shown in Table $\mathrm{S} 2$.

The $\rho_{0}-T^{-1 / 4}$ curves, $I-V$ curves, and MR-magnetic field curves were tested on a self-built magnetic transportation measure system and multi-parameter physical properties measure system (PPMS), the pellets were cold-pressed under pressure of $30 \mathrm{MPa}$. The pellets were sprayed with $30 \mathrm{~nm}$ thick gold film on each side for eliminating contact resistance as much as possible and then connected to PPMS by gold wire and conductive silver adhesives. The specific resistance $\rho$ could be expressed as

$$
\rho=(R \times S) / L
$$

where $R$ is the resistance, $S$ is the cross section area (herein we use the area of the gold film on each size), $L$ is the thickness of the sample pellet.

The temperature dependence zero-bias resistivity $\rho_{0}$ for all the samples is measured by applying a constant current and corrected from the linear region of the $I-V$ curves at different temperature points.

MR at certain magnetic field $(H)$ could be expressed as

$$
\operatorname{MR}(H)=\left(\rho_{H}-\rho_{0}\right) / \rho_{0}
$$

where $\rho_{H}$ is the specific resistance of the sample at magnetic field $H, \rho_{0}$ is the specific resistance of the sample at zero-field. For most of the measurements the voltage is tuned to get about $0.01 \mu \mathrm{A}$ current for comparison. 

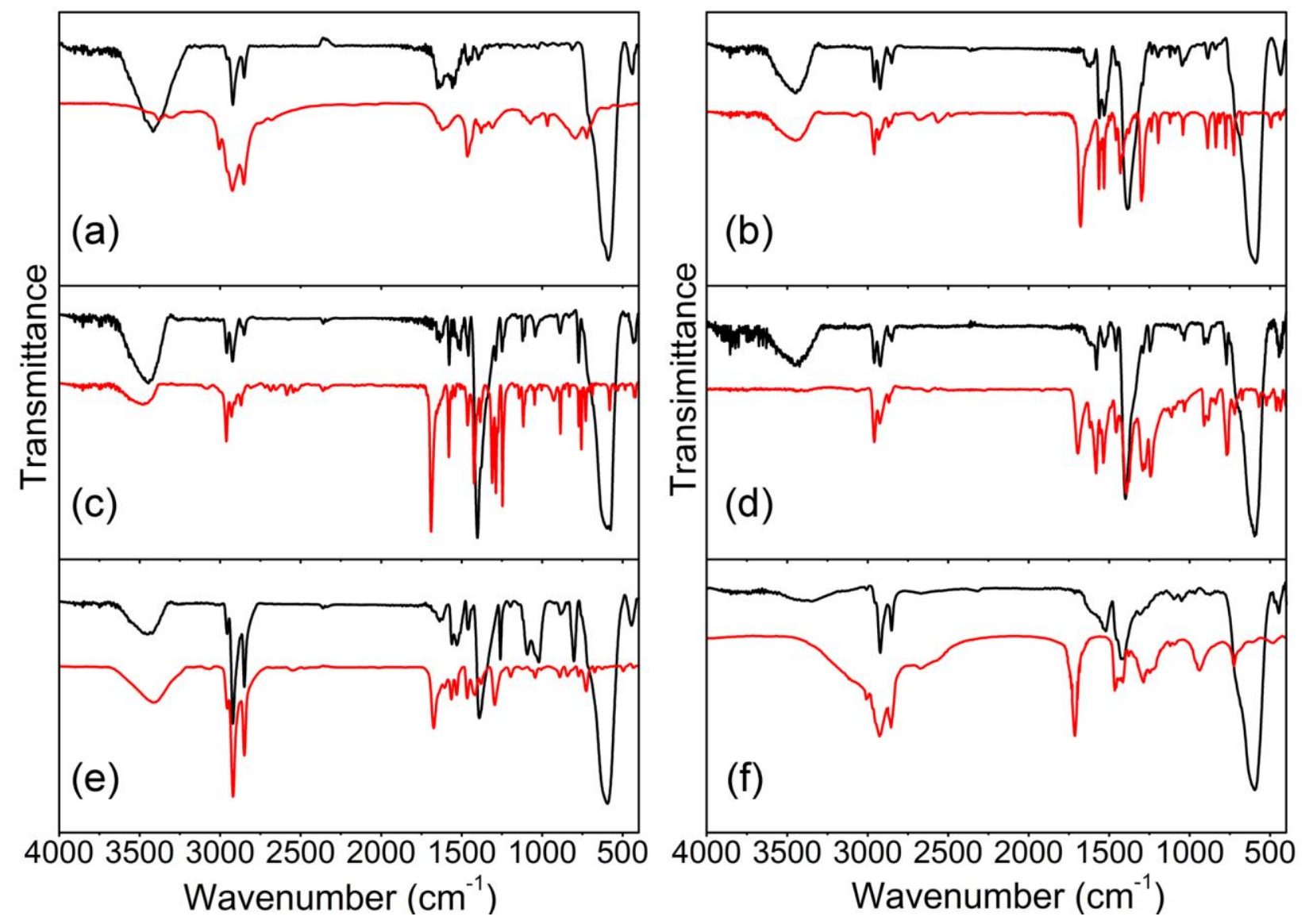

Figure S1. FT-IR spectra of the synthesized NPs (black curves), including the spectra of the corresponding ligands (red curves). (a) OA-NPs, OA; (b) $\mathrm{L}_{1}-\mathrm{NPs}, \mathrm{L}_{1}$; (c) $\mathrm{L}_{2}-\mathrm{NPs}_{2} \mathrm{~L}_{2}$; (d) $\mathrm{L}_{3}-\mathrm{NPs}$, $\mathrm{L}_{3}$; (e) $\mathrm{L}_{1}$ '-NPs, $\mathrm{L}_{1}$; ; (f) OC-NPs, OC. 
Table S1. Assignment of the main absorption bands ${ }^{\mathrm{a}}$ in the IR spectra of $\mathrm{L}_{1}, \mathrm{~L}_{2}, \mathrm{~L}_{3}, \mathrm{~L}_{1}$,, $\mathrm{OC}$, and the corresponding NPs.

\begin{tabular}{|c|c|c|c|c|c|c|c|c|c|c|}
\hline $\begin{array}{c}\text { mode } \\
\text { assignment }\end{array}$ & $\mathrm{L}_{1}$ & $\mathrm{~L}_{1}-\mathrm{NPs}$ & $\mathrm{L}_{2}$ & $\mathrm{~L}_{2}$-NPs & $\mathrm{L}_{3}$ & $\mathrm{~L}_{3}-\mathrm{NPs}$ & $\mathrm{L}_{1}$, & $\mathrm{L}_{1}{ }^{\prime}-\mathrm{NPs}$ & $\mathrm{OC}$ & OC-NPs \\
\hline \multirow[t]{4}{*}{$\nu \mathrm{C}-\mathrm{H}$} & & & & & & & & & $3008 \mathrm{w}$ & \\
\hline & $2959 \mathrm{~m}$ & $2959 \mathrm{~m}$ & $2961 \mathrm{~m}$ & $2959 \mathrm{~m}$ & $2958 \mathrm{~m}$ & $2960 \mathrm{~m}$ & $2955 \mathrm{~m}$ & $2957 \mathrm{~m}$ & $2952 \mathrm{~m}$ & $2954 \mathrm{w}$ \\
\hline & $2931 \mathrm{~m}$ & $2923 \mathrm{~m}$ & $2929 \mathrm{w}$ & $2923 \mathrm{~m}$ & $2925 \mathrm{~m}$ & $2921 \mathrm{~m}$ & $2920 \mathrm{~s}$ & $2920 \mathrm{~s}$ & $2927 \mathrm{~s}$ & $2922 \mathrm{~s}$ \\
\hline & $2868 \mathrm{w}$ & $2852 \mathrm{w}$ & $2870 \mathrm{w}$ & $2852 \mathrm{w}$ & $2868 \mathrm{w}$ & $2850 \mathrm{w}$ & $2851 \mathrm{~s}$ & $2850 \mathrm{~s}$ & $2855 \mathrm{~s}$ & $2852 \mathrm{~m}$ \\
\hline$v \mathrm{C}=\mathrm{O}$ and & $1677 \mathrm{~s}$ & & $1690 \mathrm{~s}$ & & $1694 \mathrm{~s}$ & & $1674 \mathrm{~m}$ & & $1711 \mathrm{~s}$ & \\
\hline \multirow{3}{*}{$v \mathrm{C}-\mathrm{O}$} & & $1618 \mathrm{w}$ & & $1636 \mathrm{w}$ & & $1617 \mathrm{w}$ & & $1637 \mathrm{w}$ & & $1630 \mathrm{w}$ \\
\hline & $1299 \mathrm{~s}$ & & $1274 \mathrm{w}$ & & $1278 \mathrm{~s}$ & & $1294 \mathrm{~m}$ & & $1287 \mathrm{~m}$ & \\
\hline & & $1386 \mathrm{~s}$ & & $1402 \mathrm{~s}$ & & $1399 \mathrm{~s}$ & & $1391 \mathrm{~s}$ & & $1410 \mathrm{~s}$ \\
\hline$v \mathrm{Ph}$ & & & $1580 \mathrm{~m}$ & $1578 \mathrm{w}$ & $1581 \mathrm{~s}$ & $1578 \mathrm{~m}$ & & & & \\
\hline \multirow[t]{2}{*}{$v \mathrm{C}=\mathrm{C}$} & $1563 \mathrm{~m}$ & $1561 \mathrm{~m}$ & $1560 \mathrm{w}$ & $1558 \mathrm{w}$ & & & $1564 \mathrm{w}$ & $1560 \mathrm{w}$ & & \\
\hline & $1532 \mathrm{~m}$ & $1531 \mathrm{~m}$ & $1541 \mathrm{w}$ & $1540 \mathrm{w}$ & $1537 \mathrm{~s}$ & $1534 \mathrm{w}$ & $1531 \mathrm{w}$ & $1530 \mathrm{w}$ & & \\
\hline$\delta \mathrm{CH}_{2}$ & $1458 \mathrm{w}$ & $1457 \mathrm{w}$ & $1463 \mathrm{w}$ & $1458 \mathrm{w}$ & $1456 \mathrm{~m}$ & $1458 \mathrm{w}$ & $1466 \mathrm{w}$ & $1459 \mathrm{w}$ & $1464 \mathrm{~m}$ & $1452 \mathrm{~m}$ \\
\hline$\delta \mathrm{O}-\mathrm{H}$ & $1430 \mathrm{~m}$ & & $1422 \mathrm{~m}$ & & $1391 \mathrm{~s}$ & & $1418 \mathrm{~s}$ & & $1423 \mathrm{~m}$ & \\
\hline$\delta \mathrm{CH}_{3}$ & $1378 \mathrm{~m}$ & $-\mathrm{-O}^{\mathrm{b}}$ & $1384 \mathrm{~m}$ & $--^{b}$ & $1377 \mathrm{~m}$ & $-\mathrm{-}^{\mathrm{b}}$ & $1381 \mathrm{w}$ & $---{ }^{b}$ & $1378 \mathrm{w}$ & $-{ }^{b}{ }^{b}$ \\
\hline \multirow[t]{2}{*}{$\delta \mathrm{S}-\mathrm{CH}_{2}$} & $1291 \mathrm{~m}$ & $1291 \mathrm{~m}$ & $1287 \mathrm{~s}$ & $1289 \mathrm{w}$ & $1291 \mathrm{~s}$ & $1289 \mathrm{w}$ & $---{ }^{b}$ & & & \\
\hline & $1238 \mathrm{w}$ & $1234 \mathrm{w}$ & $1245 \mathrm{~s}$ & $1248 \mathrm{~m}$ & $1243 \mathrm{~s}$ & $1247 \mathrm{~m}$ & $1244 \mathrm{w}$ & $1259 \mathrm{~m}$ & & \\
\hline \multirow[t]{3}{*}{$v \mathrm{~S}-\mathrm{C}-\mathrm{S}$} & $1042 \mathrm{w}$ & $1047 \mathrm{w}$ & $1046 \mathrm{w}$ & $1043 \mathrm{w}$ & $1033 \mathrm{w}$ & $1034 \mathrm{w}$ & $1043 \mathrm{w}$ & $---{ }^{b}$ & & \\
\hline & & & & & $910 \mathrm{w}$ & $909 \mathrm{w}$ & & & & \\
\hline & $888 \mathrm{w}$ & $887 \mathrm{w}$ & $886 \mathrm{w}$ & $888 \mathrm{w}$ & $883 \mathrm{w}$ & $887 \mathrm{w}$ & $891 \mathrm{w}$ & $886 \mathrm{w}$ & & \\
\hline \multirow{2}{*}{ Fe-O lattice } & & $800-500$ & & $800-500$ & & $800-500$ & & $800-500$ & & $800-500$ \\
\hline & & $\mathrm{s}, \mathrm{br}$ & & $\mathrm{s}, \mathrm{br}$ & & $\mathrm{s}, \mathrm{br}$ & & $\mathrm{s}, \mathrm{br}$ & & $\mathrm{s}, \mathrm{br}$ \\
\hline
\end{tabular}

${ }^{a}$ unit in $\mathrm{cm}^{-1}$; s: strong; $\mathrm{m}$ : middle; w: weak, br: broad.

${ }^{\mathrm{b}}$ bands that cannot be discerned due to other intense band coverage. 
Table S2. Mass percentage of $\mathrm{Fe}, \mathrm{Fe}_{3} \mathrm{O}_{4}$ and organic layer ${ }^{\mathrm{a}}$ in $\mathrm{OA}-, \mathrm{L}_{1^{-}}, \mathrm{L}_{2^{-}}, \mathrm{L}_{3^{-}}, \mathrm{L}_{1}$, , and OC-NPs and the packing density ${ }^{\mathrm{b}}$ of corresponding samples.

\begin{tabular}{c|cccc}
\hline \multirow{2}{*}{ OA-NPs } & $m(\mathrm{Fe})(\mathrm{wt} \%)$ & $m\left(\mathrm{Fe}_{3} \mathrm{O}_{4}\right)(\mathrm{wt} \%)$ & $m(\mathrm{~L})(\mathrm{wt} \%)$ & $n\left(1 / \mathrm{nm}^{2}\right)^{\mathrm{b}}$ \\
\cline { 2 - 4 } $\mathrm{L}_{1}-\mathrm{NPs}$ & 67.9 & 93.8 & 6.2 & 0.75 \\
\cline { 2 - 4 } $\mathrm{L}_{2}-\mathrm{NPs}$ & 61.5 & 84.9 & 15.1 & 1.36 \\
\cline { 2 - 4 } $\mathrm{L}_{3}-\mathrm{NPs}$ & 60.3 & 83.2 & 16.8 & 1.36 \\
\cline { 2 - 4 } $\mathrm{L}_{1}{ }^{\prime}-\mathrm{NPs}$ & 56.8 & 78.4 & 21.6 & 1.56 \\
\cline { 2 - 4 } OC-NPs & 57.1 & 78.9 & 21.1 & 1.84 \\
\hline
\end{tabular}

a The mass percentage of $\mathrm{Fe}_{3} \mathrm{O}_{4}$ is converted from the mass percentage of Fe determined by F-AAS. The mass percentage of organic layer $m(\mathrm{~L})$ equals to $1-m\left(\mathrm{Fe}_{3} \mathrm{O}_{4}\right)$.

b The packing density $n$ is obtain by assuming a uniform $5.7 \mathrm{~nm}$ diameter and $5.2 \mathrm{~g} / \mathrm{cm}^{3}$ density for a sphere $\mathrm{Fe}_{3} \mathrm{O}_{4}$ core.

Table S3. Atomic percentage ${ }^{\mathrm{a}}$ of the main elements in $\mathrm{OA}-, \mathrm{L}_{1^{-}}, \mathrm{L}_{2^{-}}, \mathrm{L}_{3^{-}}, \mathrm{L}_{1}{ }^{\text {'-, }}$, and OC-NPs.

\begin{tabular}{c|c|c|c|c|c|c}
\hline & OA-NPs & $\mathrm{L}_{1}$-NPs & $\mathrm{L}_{2}$-NPs & $\mathrm{L}_{3}$-NPs & $\mathrm{L}_{1}{ }^{\prime}$-NPs & \multicolumn{2}{c}{ OC-NPs } \\
\hline $\mathrm{C}$ & 57.92 & 40.52 & 47.12 & 47.26 & 51.99 & 46.58 \\
$\mathrm{O}$ & 26.85 & 31.55 & 27.83 & 20.75 & 28.18 & 42.14 \\
$\mathrm{~S}$ & 0.00 & 8.52 & 8.39 & 13.57 & 5.47 & 0.00 \\
$\mathrm{~N}$ & 2.73 & 0.00 & 0.00 & 0.00 & 0.00 & 0.00 \\
$\mathrm{Fe}$ & 12.50 & 19.40 & 16.66 & 18.43 & 14.36 & 11.28 \\
\hline
\end{tabular}

${ }^{\mathrm{a}}$ Only C, O, S, N and Fe are included and the sum of their percentage is $100 \%$. 


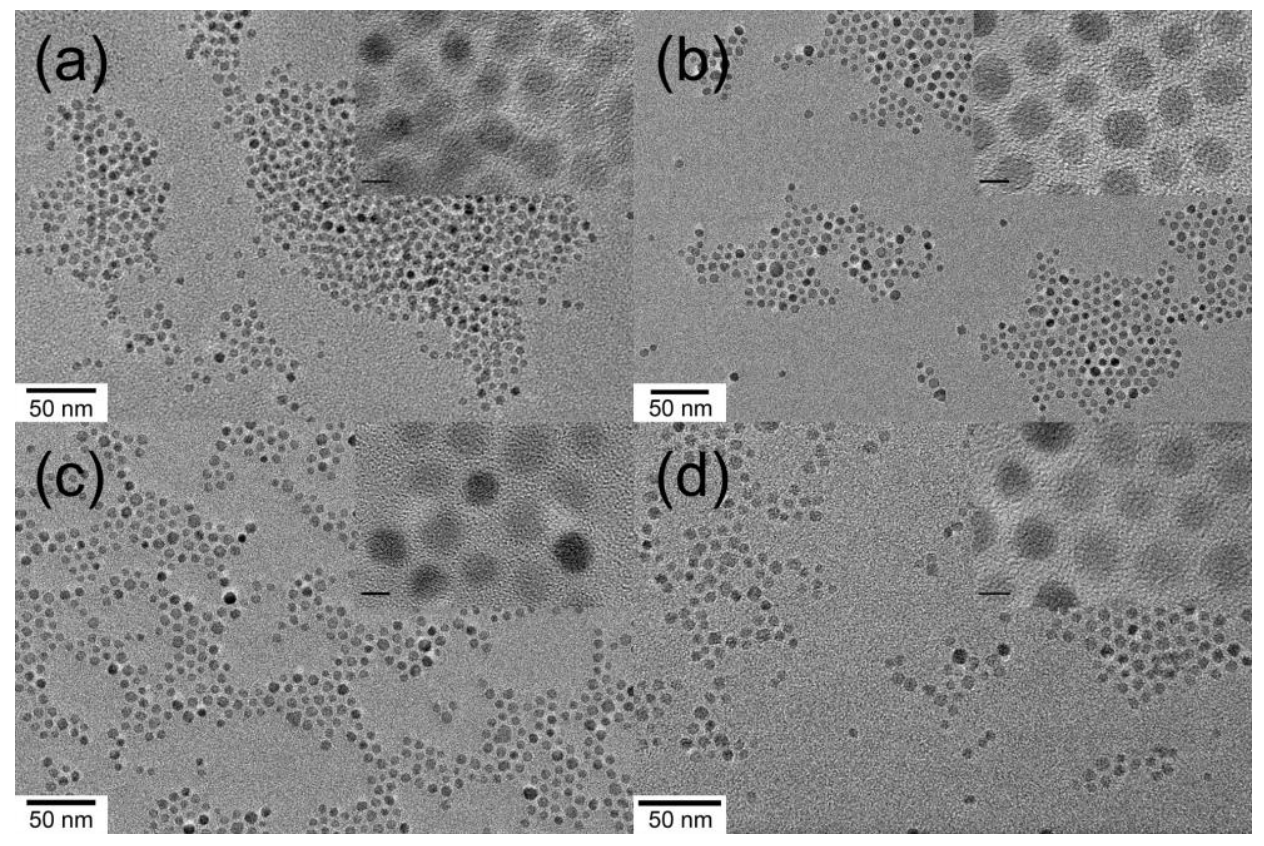

Figure S2. TEM images of (a) $\mathrm{L}_{1}-\mathrm{NPs}$, (b) $\mathrm{L}_{2}-\mathrm{NPs}$, (c) $\mathrm{L}_{3}-\mathrm{NPs}$, and (d) $\mathrm{L}_{1}$ '-NPs. The insert figures are HRTEM images of corresponding samples, and the scale bar of insert figure is $5 \mathrm{~nm}$.
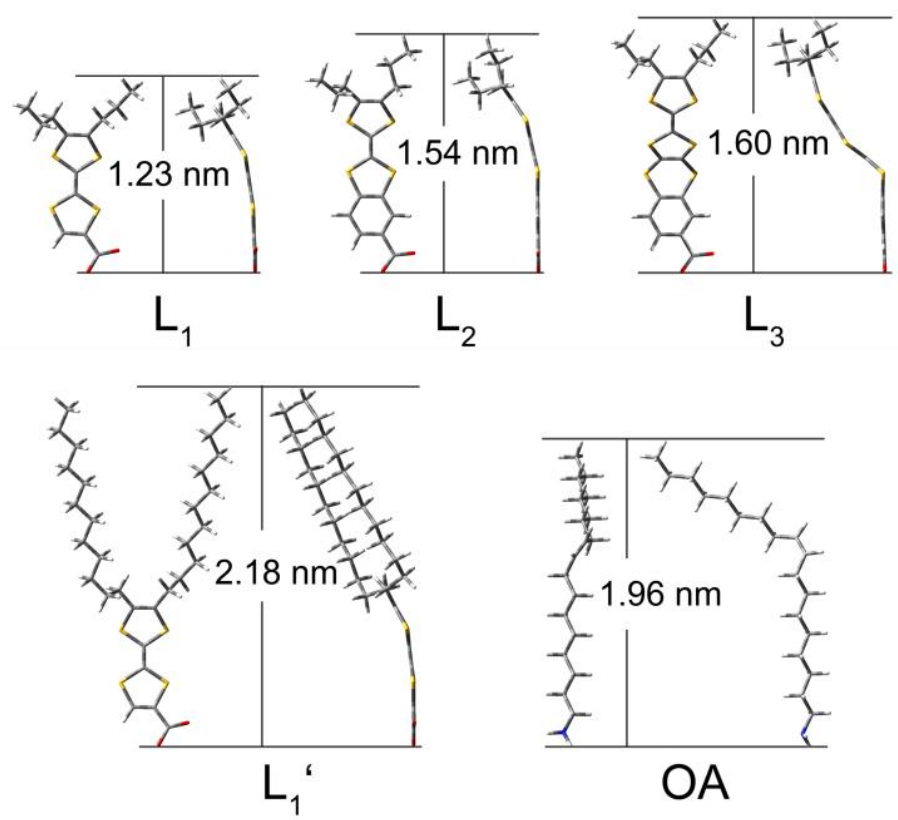

Figure S3. Theoretical molecular lengths of $\mathrm{L}_{1^{-}}, \mathrm{L}_{2^{-}}, \mathrm{L}_{3^{-}}$, and $\mathrm{L}_{1}{ }^{\prime}-\mathrm{COO}^{-}$and $\mathrm{OA}$ obtained by DFT calculations. 


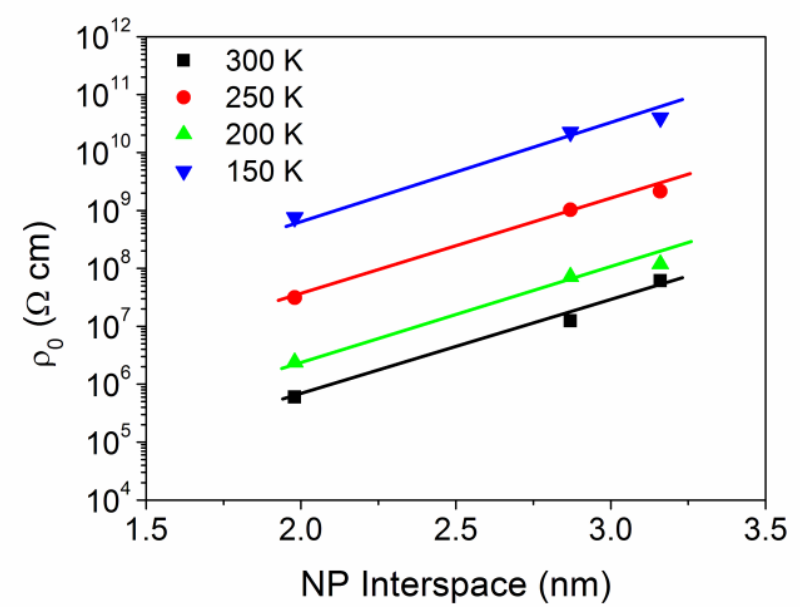

Figure S4. Plot of $\rho$ vs. NP interspace of $\mathrm{L}_{1-3}$-NPs at $300 \mathrm{~K}, 250 \mathrm{~K}, 200 \mathrm{~K}$ and $150 \mathrm{~K}$, respectively. $\rho_{0}$ is plotted in a logarithmic scale. The solid lines are guides to the eyes.

(a)
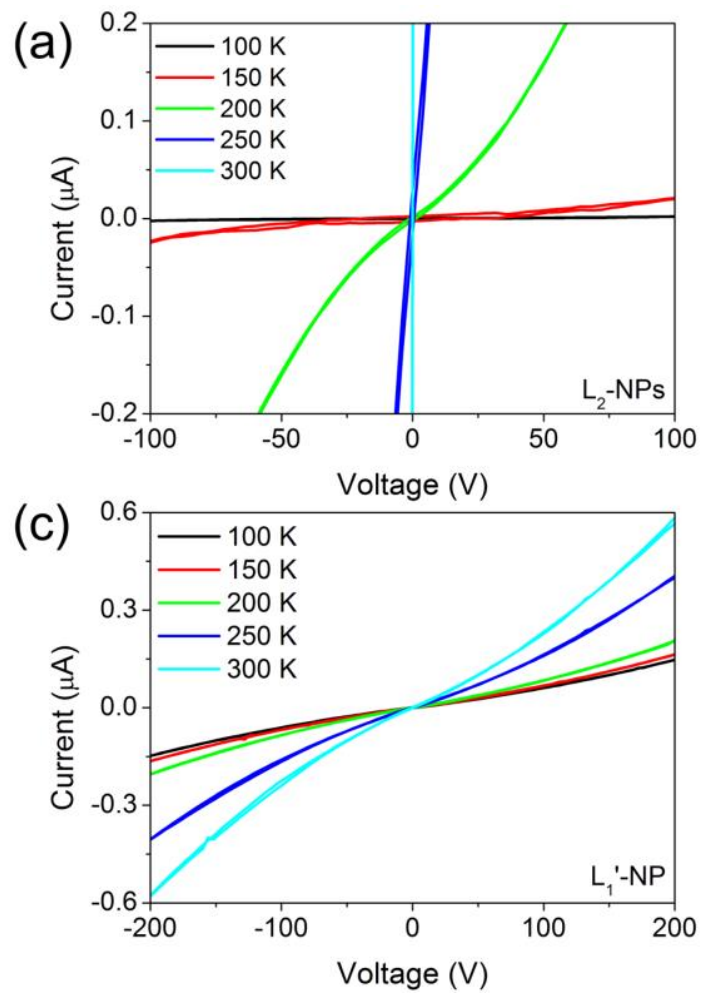

(b)

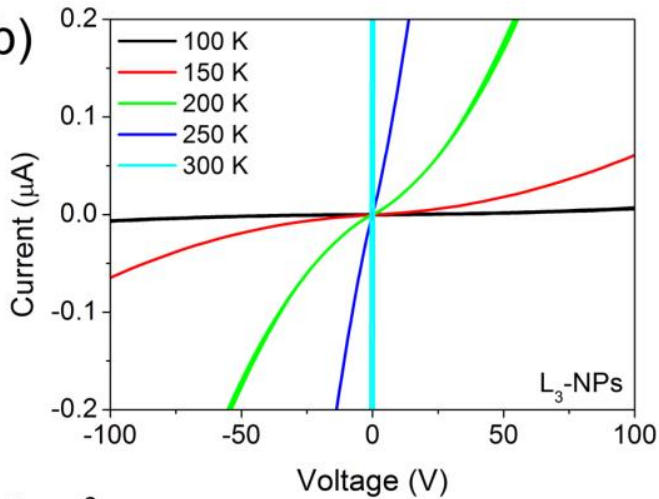

(d)

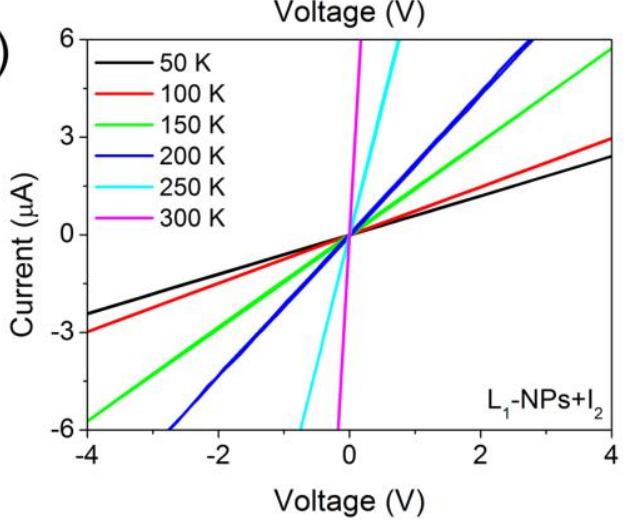

Figure S5. $I-V$ curves of (a) $\mathrm{L}_{2}-\mathrm{NPs}$, (b) $\mathrm{L}_{3}-\mathrm{NPs}$, (c) $\mathrm{L}_{1}$ '-NPs, and (d) $\mathrm{L}_{1}-\mathrm{NPs}+\mathrm{I}_{2}$ at different temperatures. 


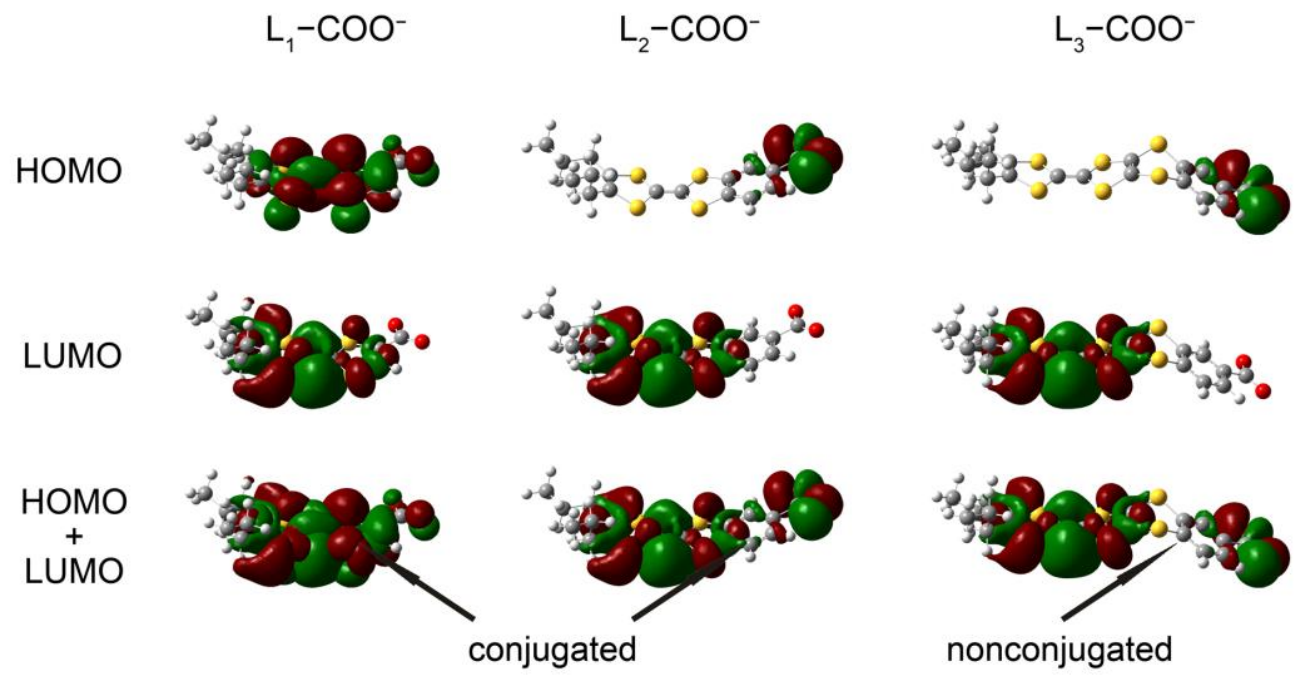

Figure S6. Frontier orbital distributions of $\mathrm{L}_{1^{-}}, \mathrm{L}_{2^{-}}$, and $\mathrm{L}_{3}-\mathrm{COO}^{-}$by DFT calculations. 

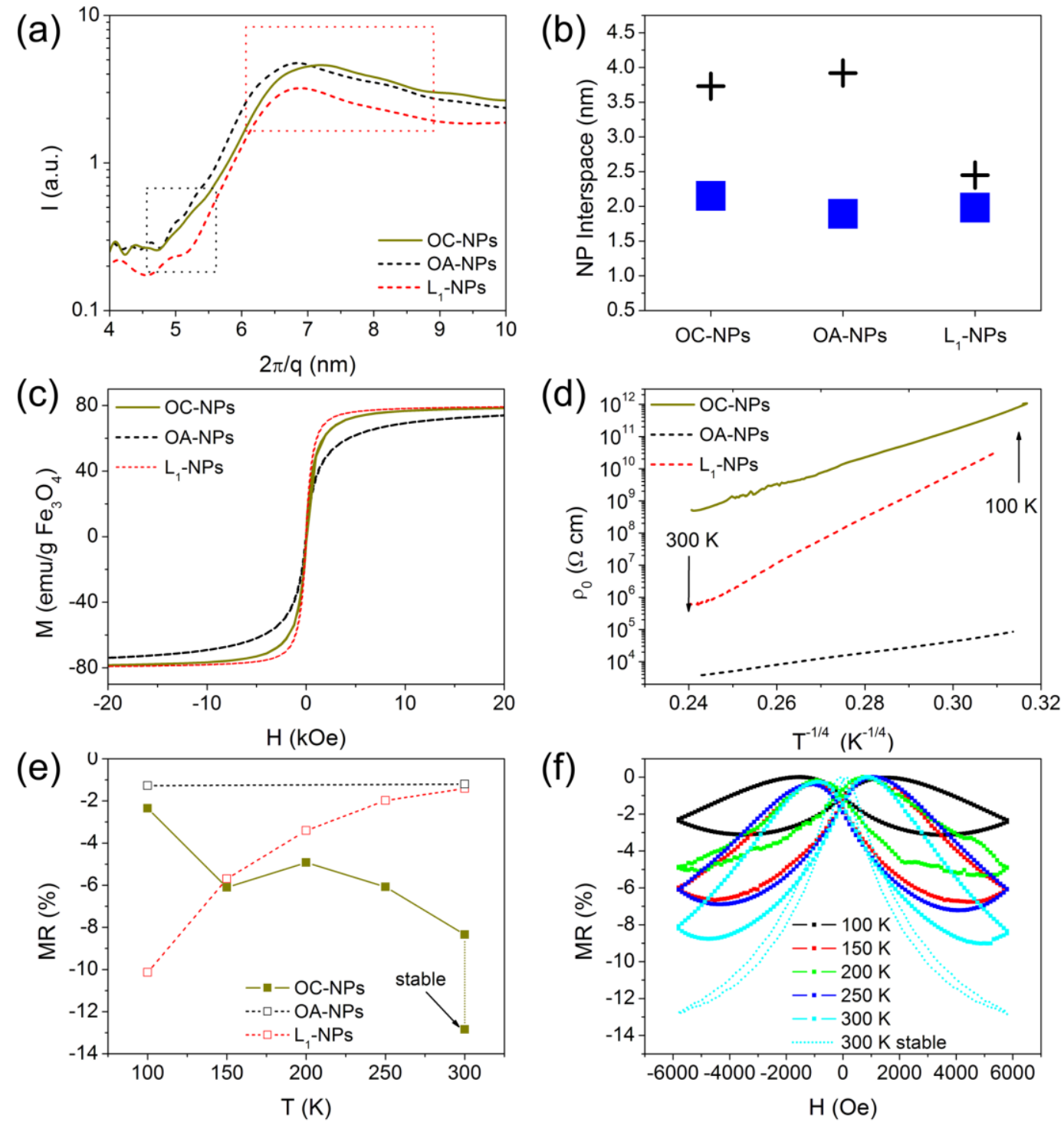

Figure S7. (a) Powder SAXS patterns of the OC-, OA-, and $\mathrm{L}_{1}$-NPs. $I$ is plotted in a logarithmic scale. (b) Statistical NP interspaces of the functionalized NPs obtained from SAXS (blue cube). The black cross represents the double length of corresponding ligand obtained from DFT calculation. (c) Magnetic hysteresis loops measured at $100 \mathrm{~K}$ for OC-, OA-, and $\mathrm{L}_{1}-\mathrm{NPs}$. (d) Zero-bias resistivity $\rho_{0}$ of OC-, OA-, and $\mathrm{L}_{1}-\mathrm{NPs}$ as a function of $T^{-1 / 4} \cdot \rho_{0}$ is plotted in a logarithmic scale. (e) Temperature dependent MR of the OC-, OA-, and $\mathrm{L}_{1}-\mathrm{NPs}$ at $5.8 \mathrm{kOe}$. The arrow point of OC-NP represent MR ratio before the sample getting unstable. (f) Magnetic field MR of the OC-NPs at different temperatures. The dot line curve represents MR before the sample getting unstable. 
(a)

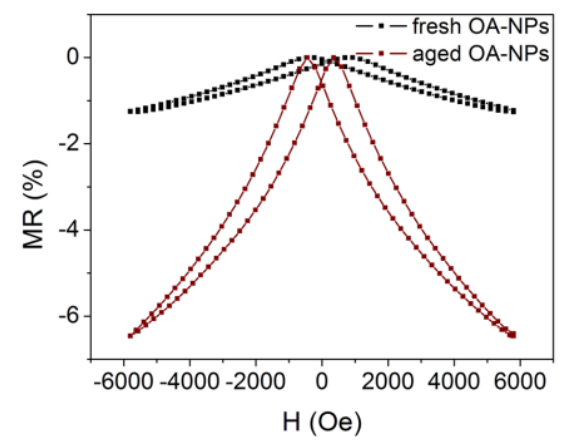

(b) Voltage (V)

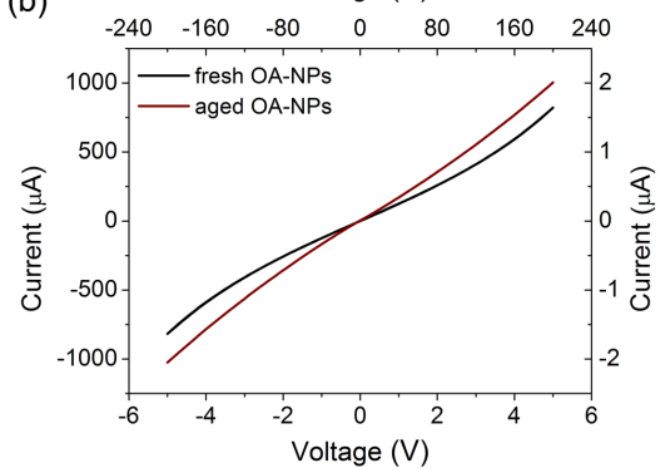

Figure S8. (a) MR-magnetic field curves of freshly prepared OA-NPs and OA-NPs after 6 month storage at $300 \mathrm{~K}$. (b) $I-V$ curves of freshly prepared OA-NPs (bottom - left axis) and OA-NPs after 6 month storage (top - right axis) at $300 \mathrm{~K}$.

(a)
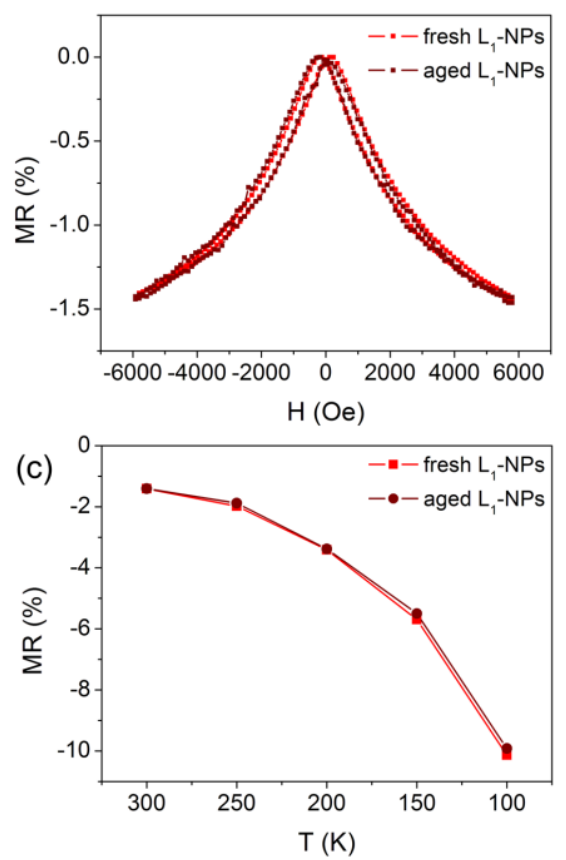

(b)

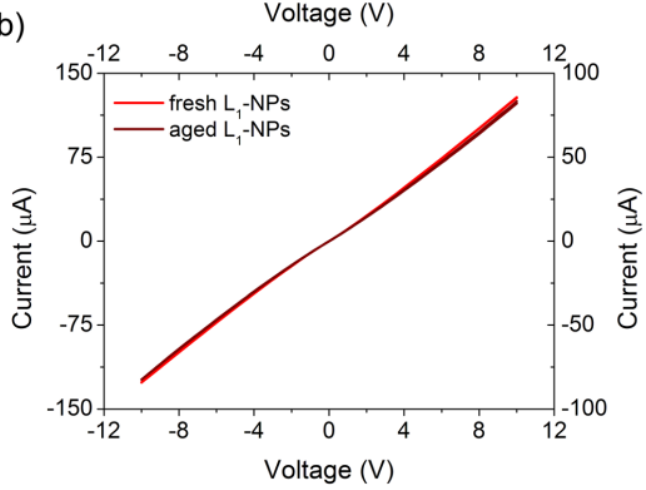

Figure S9. (a) MR-magnetic field curves of freshly prepared $L_{1}$-NPs and $L_{1}$-NPs after 6 month storage at $300 \mathrm{~K}$. (b) $I-V$ curves of freshly prepared $\mathrm{L}_{1}$-NPs (link to bottom and left axis) and $\mathrm{L}_{1}$-NPs after 6 month storage (link to top and right axis) at $300 \mathrm{~K}$. (c) Temperature dependence magnetoresistance of fresh prepared $\mathrm{L}_{1}$-NPs and $\mathrm{L}_{1}$-NPs after 6 month storage at $5.8 \mathrm{kOe}$. 
(a)
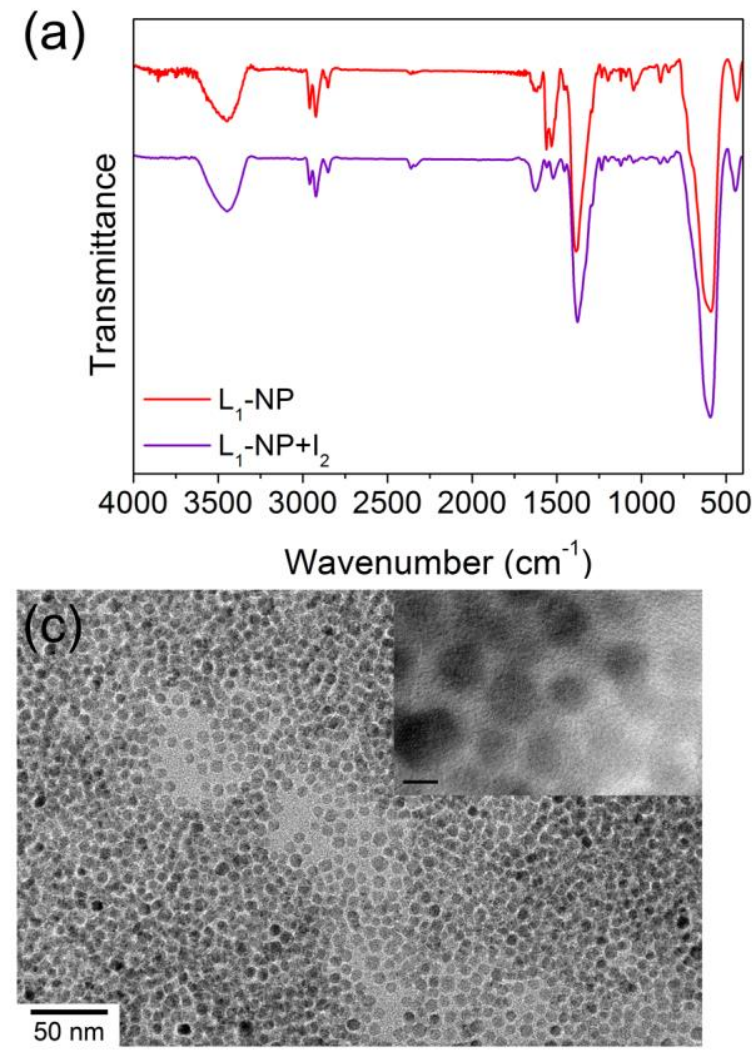

(b)

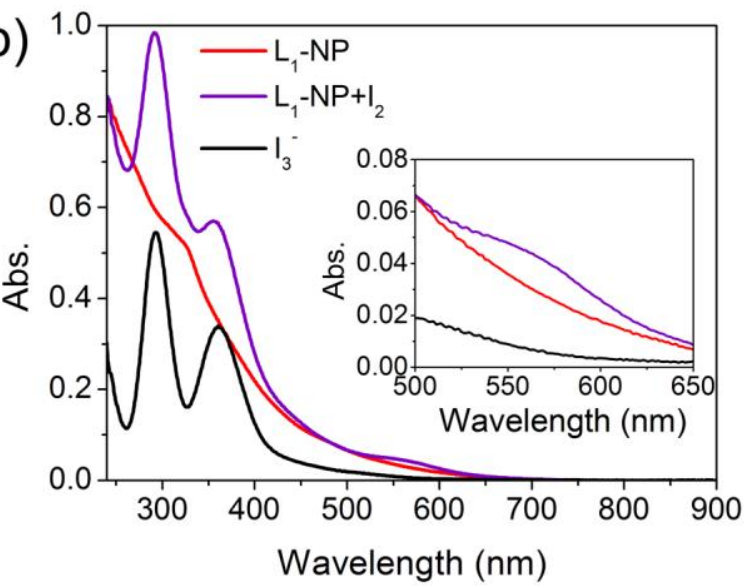

(d)

Hexane

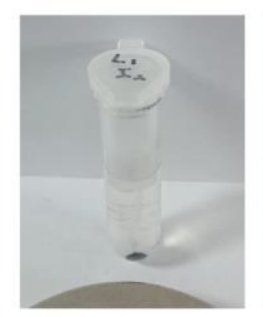

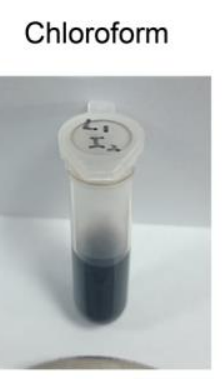

Ethanol

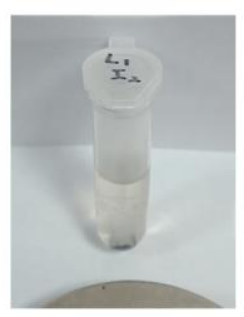

Figure S10. (a) FT-IR spectra of $\mathrm{L}_{1}-\mathrm{NPs}$ and $\mathrm{L}_{1}-\mathrm{NPs}+\mathrm{I}_{2}$. (b) UV-vis spectra of $\mathrm{L}_{1}-\mathrm{NPs}$, $\mathrm{L}_{1}-\mathrm{NPs}+\mathrm{I}_{2}$ and $\mathrm{I}_{3}{ }^{-}$in chloroform:ethanol $(3: 1 \mathrm{v} / \mathrm{v})$. The inset: the zoom-in spectra between 500-650 nm. (c) TEM images of $\mathrm{L}_{1}-\mathrm{NPs}+\mathrm{I}_{2}$. The inset: the higher magnification image of the NP assembly (scale bar $=5 \mathrm{~nm}$ ). (d) Photographic illustration of $\mathrm{L}_{1}-\mathrm{NPs}+\mathrm{I}_{2}$ samples dispersibility in hexane, chloroform and ethanol. 
Table S4. Mass percentage ${ }^{\mathrm{a}}$ of the main elements in $\mathrm{L}_{1}-\mathrm{NPs}+\mathrm{I}_{2}$.

\begin{tabular}{c|cc}
\hline & \multicolumn{2}{c}{$\mathrm{L}_{1}-\mathrm{NPs}_{\mathrm{s}}+\mathrm{I}_{2}$} \\
\hline & exp. & cal. $^{\mathrm{b}}$ \\
$\mathrm{C}$ & 17.62 & 5.52 \\
$\mathrm{O}$ & 20.77 & 22.53 \\
$\mathrm{~S}$ & 10.31 & 6.79 \\
$\mathrm{Fe}$ & 42.55 & 56.17 \\
$\mathrm{I}$ & 8.77 & 8.99 \\
\hline
\end{tabular}

${ }^{a}$ Only C, O, S, Fe and I are included and the sum of their percentage is $100 \%$.

${ }^{\mathrm{b}}$ The theoretical compositions are calculate using experiment grafting density data from Table $\mathrm{S} 2$ (1.36 molecules per $\mathrm{nm}^{2}$ on a $5.7 \mathrm{~nm} \mathrm{NP}$ core) and assuming 2/3 of surface ligands is converted to TTF radical in the form of $\left(\mathrm{TTF}^{+\bullet}\right)\left(\mathrm{I}_{3}{ }^{-}\right)$after oxidized by $\mathrm{I}_{2} \cdot{ }^{10}$ 


\section{Reference}

1. Hasegawa, M.; Takano, J.; Enozawa, H.; Kuwatani, Y.; Iyoda, M. Aggregation of Star-Shaped Tris(tetrathiafulvalenylethynyl) Benzene in Solution and in the Solid State. Tetrahedron Lett. 2004, 45, 4109-4112.

2. Kotha, S.; Shah, V. R.; Mandal, K. Formation of Arenes via Diallylarenes: Strategic utilization of Suzuki-Miyaura Cross-Coupling, Claisen Rearrangement and Ring-Closing Metathesis. Adv. Synth. Catal. 2007, 349, 1159-1172.

3. Segura, J. L.; Priego, E. M.; Martín, N.; Luo, C.; Guldi, D. M. A New Photoactive and Highly Soluble $\mathrm{C}_{60}-\mathrm{TTF}-\mathrm{C}_{60}$ Dimer: Charge Separation and Recombination. Org. Lett. 2000, 2, 4021-4024.

4. Svenstrup, N.; Rasmussen, K. M.; Hansen, T. K.; Becher, J. The Chemistry of TTFTT .1. New Efficient Synthesis And Reactions of Tetrathiafulvalene-2,3,6,7-Tetrathiolate (TTFTT) - an Important Building-Block in TTF-Syntheses. Synthesis 1994, 809-812.

5. Hansen, J. A.; Becher, J.; Jeppesen, J. O.; Levillain, E.; Nielsen, M. B.; Petersen, B. M.; Petersen, J. C.; Sahin, Y. Synthesis and Non-Linear Optical Properties of Monopyrrolotetrathiafulvalene Derived Donor- $\pi$-Acceptor Dyads. J. Mater. Chem. 2004, 14, 179-184.

6. Surpateanu, G. G.; Lungu, C. N.; Fourmentin, S.; Landy, D.; Surpateanu, G.; Avarvari, N. A Competitive Sensing System Based on Cyclobis(paraquat-p-phenylene) and a New $\beta$-Cyclodextrin-Tetrathiafulvalene Derivative. Supramol. Chem. 2009, 21, 372-378.

7. Sun, J. B.; Lu, X. F.; Shao, J. F.; Cui, Z. L.; Shao, Y.; Jiang, G. Y.; Yu, W.; Shao, X. F. Straightforward Access to Aryl-Substituted/Fused 1,3-Dithiole-2-Chalcogenones by $\mathrm{Cu}$-Catalyzed C-S Coupling between Aryl Iodides and Zinc-Thiolate Complex (TBA $)_{2}\left[\mathrm{Zn}(\mathrm{DMIT})_{2}\right]$. Rsc Adv. 2013, 3, 10193-10196.

8. Rasband, W. ImageJ, 1.48v; National Institutes of Health: USA, 2014.

9. Xu, J. Nano Measurer, 1.2.0; Fudan University: P.R.C., 2008.

10. Yang, S.; Brooks, A. C.; Martin, L.; Day, P.; Pilkington, M.; Clegg, W.; Harrington, R. W.; Russo, L.; Wallis, J. D. New Chiral Organosulfur Donors Related to Bis(ethylenedithio)tetrathiafulvalene. Tetrahedron 2010, 66, 6977-6989. 